\title{
PERLINDUNGAN HUKUM BAGI KONSUMEN TERHADAP PRODUK KOSMETIK IMPOR TANPA IZIN EDAR YANG DIJUAL SECARA ONLINE
}

\author{
Oleh : \\ Ni Kadek Diah Sri Pratiwi * \\ Made Nurmawati** \\ Program Kekhususan Hukum Bisnis Fakultas Hukum Universitas \\ Udayana
}

\begin{abstract}
ABSTRAK
Produk Kosmetik impor merupakan salah satu barang yang sangat banyak dijual secara online. Kebutuhan dan permintaan masyarakat akan kosmetik dalam menunjang penampilan khususnya bagi perempuan berdampak meningkatnya industri kosmetik baik yang diproduksi dalam negeri maupun diimpor dari luar negeri. Namun tidak semua produk kosmetik yang dijual secara online telah memiliki izin edar dari BPOM. Oleh karena itu perlindungan konsumen diperlukan untuk melindungi hak-hak konsumen yang telah ditetapkan dalam Undang-Undang Nomor 8 Tahun 1999 tentang Perlindungan Konsumen, atas kosmetik impor yang tidak memiliki izin edar. Tujuan dari penulisan jurnal ilmiah ini yaitu untuk lebih memahami pengaturan perlindungan hukum terhadap konsumen atas produk kosmetik impor yang tidak memiliki izin edar dan mengetahui bentuk pengawasan BBPOM Denpasar atas produk kosmetik yang dijual secara online. Metode penelitian yang digunakan adalah penelitian hukum empiris dengan pendekatan perundangundangan dan pendekatan fakta. Data dan sumber data yang digunakan dalam penelitian ini yaitu bahan hukum primer berupa wawancara dengan informan dari pihak BBPOM Denpasar dan bahan hukum sekunder yang terdiri dari bahan hukum primer yaitu peraturan perundnag-undangan terkait dan bahan hukum sekunder berupa buku-buku dan hasil penelitian terdahulu. Dari hasil penelitian, dapat disimpulkan bahwa implementasi perlindungan hukum terhadap konsumen atas produk kosmetik impor yang dijual secara online belum efektif diterapkan.Karena masih banyaknya

*) Makalah ini merupakan diluar ringkasan skripsi

*) Ni Kadek Diah Sri Pratiwi adalah Mahasiswi Fakultas Hukum Universitas Udayana,diah_sripratiwi@yahoo.com

**) Made Nurmawati adalah Dosen Pengajar Hukum Tata Negara Fakultas Hukum Universitas Udayana, sebagai penulis II
\end{abstract}


produk kosmetik imporyang dijual secara online dan tidak memenuhi standar mutu yang ditetapkan BPOM.

\title{
Kata Kunci : Perlindungan Konsumen, Kosmetik, Impor, Izin Edar, Online.
}

\begin{abstract}
Imported Cosmetic Products is one item that is very much sold online. The needs and demands of the community for cosmetics to support their appearance, especially for women, have an impact on the increase in the cosmetics industry, both domestically produced and imported from abroad. However, not all cosmetic products sold online have obtained marketing authorization from BPOM. Therefore, consumer protection is needed to protect consumer rights stipulated in Law Number 8 of 1999 concerning Consumer Protection, for cosmetics that do not have distribution permits. The purpose of writing this scientific journal is to better understand legal protection for consumers of imported cosmetic products that do not have marketing permits and know the forms of BBPOM Denpasar supervision of cosmetic products sold online. The research method used is empirical legal research with a legal approach and factual approach. Data and sources of data used in this study are primary legal material in the form of interviews with informants from BBPOM Denpasar and secondary legal materials consisting of primary legal materials, namely related regulations and secondary legal materials in the form of books and results of previous research. From the results of the study, it can be concluded that the implementation of legal protection for consumers of imported cosmetic products sold online has not been effectively applied. Because there are still many cosmetic products sold online and not meeting the quality standards set by BPOM.
\end{abstract}

\section{Keywords : protection, consumens, cosmetics, import, marketing authorixation, online}




\section{Pendahuluan}

\subsection{Latar Belakang}

Perkembangan teknologi dan informasi membuat suatu produk dapat dipasarkan secara global dalam media online. Produk kosmetik merupakan salah satu barang yang banyak dijual secara online. Kosmetik telah menjadi suatu kebutuhan pokok yang digunakan setiap hari untuk dapat menjaga penampilan baik laki-laki maupun perempuan. Kebutuhan akan produk-produk kosmetik tersebut merupakan peluang besar dalam sektor bisnis, terlebih lagi dengan adanya media online para pelaku usaha dapat menjual dan mempromisikan produknya baik itu produk dalam negeri maupun produk yang diimpor dari luar negeri tanpa terhalang batas wilayah. ${ }^{1}$

Dalam era perdagangan bebas ini, terdapat dua hal yang berkaitan dengan konsumen. Pertama, konsumen diuntungkan karena dengan adanya perdagangan bebas ini maka arus keluar masuk barang menjadi semakin lancar dan tidak terhambat dengan batasan wilayah atau suatu negara. Oleh karena itu konsumen lebih banyak mempunyai pilihan dalam menentukan berbagai kebutuhan, baik berupa barang atau jasa, dari segi jenis dan macam barang, mutu, merek maupun harga. Kedua, posisi konsumen di negara berkembang dirugikan, hal ini disebabkan lemahnya pengawasan di bidang standarisasi mutu barang, lemahnya produk perundangundangan, ${ }^{2}$ yang mana berakibat banyak produk kosmetik yang

1 Salsabilla, M., 2015. Perlindungan Konsumen Terhadap Produk Kosmetik Yang Dijual Secara Online Di Kota Banda Aceh, Jurnal Fakultas Hukum Universitas Syiah Kuala, h. 7

2 Celina Tri Siwi Kristiyanti, 2011, Hukum Perlindungan Konsumen, Sinar Grafika, Jakarta, h. 8 
diedarkan dipasaran tidak memenuhi standar mutu serta tidak terdaftar dan memiliki izin edar dari BPOM.

Produk-produk kosmetik saat ini beraneka ragam jenis dan merek, tidak hanya terbatas produk kosmetik dalam negeri saja namun juga produk kosmetik luar negeri seperti Taiwan, Cina, Thailand, dan Korea. Namun apakah semua produk kosmetik yang diimpor dari luar negeri tersebut aman untuk dikonsumsi oleh para konsumen khususnya di Indonesia. Hal ini berkaitan dengan kepentingan keselamatan dan kesehatan konsumen kosmetik di Indonesia.

Hasil penertiban yang dilakukan oleh Balai Besar Pengawasan Obat dan Makanan (BBPOM) Denpasar, berhasil menemukan 247 jenis kosmetik impor setara dengan 10.751 kemasan kosmetik, senilai 2 miliar rupiah yang tidak sah. Temuan illegal tersebut terdiri dari kosmetik impor yang mengandung bahan berabahaya, kosmetik impor yang belum terdaftar dan tidak memiliki izin edar, dan kosmetik impor yang dimasukkan ke dalam wilayah Indonesia secara illegal. ${ }^{3}$ Banyaknya produk kosmetik impor yang dipasarkan melalui media online menyebabkan sulitnya pengawasan dari BPOM mengenai produk kosmetik impor yang dipasarkan kepada masyarakat. Maka haruslah ada suatu bentuk perlindungan terhadap konsumen atas produk kosmetik impor yang dipakainya. Berdasarkan pemaparan tersebut penulis akan mengkaji analisa yang berjudul "PERLINDUNGAN HUKUM BAGI KONSUMEN

3 Nandhang Astika, 2018, "BPOM Sita Ribuan Kosmetik Berbahaya yang Beredar di Bali", URL : https://news.detik.com/berita/4122471/bpom-sita-ribuankosmetik-berbahaya-yang-beredar-di-bali diakses tanggal 20 September 2018 
TERHADAP PRODUK KOSMETIK IMPOR TANPA IZIN EDAR YANG DIJUAL SECARA ONLINE”

\subsection{Rumusan Masalah}

Berdasarkan latar belakang tersebut, adapun rumusan masalah yang akan dibahas sebagai berikut :

1. Bagaimana pengaturan perlindungan hukum bagi konsumen terhadap produk kosmetik impor tanpa izin edar yang dijual secara online?

2. Bagaimana bentuk pengawasan yang dilakukan oleh BBPOM Denpasar atas produk kosmetik impor tanpa izin edar yang dijual bebas secara online?

\subsection{Tujuan}

Tujuan penulisan jurnal ilmiah ini adalah untuk memahami perlindungan hukum bagi konsumen terhadap peredaran kosmetik impor tanpa izin edar dan bentuk pengawasan yang dilakukan oleh BBPOM Denpasar atas produk kosmetik impor yang dijual bebas secara online.

\section{Isi Makalah}

\subsection{Metode Penelitian}

\subsubsection{Jenis Penelitian}

Metode penelitian yang digunakan penulis dalam menjawab permasalahan yang diangkat yaitu penelitian hukum empiris. Penelitian hukum empiris merupakan istilah yang digunakan dalam 
penelitian lapangan. ${ }^{4}$ Penelitian hukum empiris dalam penelitian ini dilakukan karena adanya kesenjangan antara das sollen dengan das sein, yaitu kesenjangan antara peraturan perundang-undangan dengan kenyataannya, yakni pada penerapan ketentuan izin edat dan standar mutu kosmetik impor yang tidak sesuai dengan UUPK maupun peraturan yang telah ditetapkan BPOM.

\subsubsection{Jenis Pendekatan}

Penelitian ini menggunakan pendekatan perundanganundangan (The Statute Approach) dan pendekatan kasus (The Case Approach). ${ }^{5}$ Pendekatan perundang-undangan dengan menelaah semua peraturan perundang-undangan dan regulasi yang berkaitan dengan isi hukum dalam penelitian ini.Sedangkan pendekatan kasus pada jurnal ilmiah ini merujuk pada masih banyaknya produk kosmetik impor yang dijual online tidak memiliki izin edar dan belum memenuhi stadar mutu yang telah ditetapkan BPOM. ${ }^{6}$

\subsubsection{Bahan Hukum}

Bahan hukum yang dipergunakan dalam jurnal ilmiah ini diantaranya yaitu :

1. Bahan Hukum Primer dalam jurnal ilmiah ini didapat langsung dilapangan melalui wawancara ${ }^{7}$ dengan narasumer yaitu dari pihak BBPOM Denpasar.

${ }^{4}$ H. Zainuddin Ali, 2016, Metode Penelitian Hukum, Sinar Grafika, Jakarta, h. 24

5 Fakultas Hukum Universitas Udayana, 2013, Pedoman Pendidikan Fakultas Hukum Universitas Udayana, Denpasar, h. 80

${ }^{6}$ Peter Mahmud Marzuki, 2011, Penelitian Hukum, Kencana, Jakarta, h. 138

7 Suratman dan H. Philips Dillah, 2015, Metode Penelitian Hukum, ALFABETA, Bandung, h. 53 
2. Bahan Hukum Sekunder, bahan hukum yang erat hubungannya dengan bahan hukum primer dan dapat membantu menganalisis dan memahami bahan hukum primer, meliputi peraturan perundang-undangan diantaranya UUD NKRI 1945, Undang-Undang No. 8 Tahun 1999 tentang Perlindugan Kosumen, Peraturan Presiden No. 80 Tahun 2017 tentang Badan Pengawasan Obat dan Makanan, Peraturan Kepala Badan Pengawasan Obat dan Makanan Republik Indonesia Nomor HK.03.1.23.12.11.10052 Tahun 2011 tentang Pengawasan Produksi dan Peredaran Kosmetika. Dan bahan hukum sekunder yang terdiri dari buku-buku, hasil karya ilmiah dan hasil penelitian terdahulu. ${ }^{8}$

\subsubsection{Teknik Pengumpulan Bahan Hukum}

Penyusunan jurnal ilmiah ini menggunakan metode penelitian hukum empiris, maka teknik pengumpulan bahan hukum primer dilakukan dengan teknik wawancara dan pengumpulan bahan hukum sekunder dilakukan dengan teknik studi kepustakaan. Kemudian dikelola dengan melakukan perbandingan hasil wawancara dengan data kepustakaan yang diperoleh dandisusun secara sistematis sesuai dengan objek penelitian ini. ${ }^{9}$

${ }^{8}$ Ibid, h. 67

9 Soerjono Soekanto, 2015, Pengantar Penelitian Hukum, Cet. 3, Penerbit Universitas Indonesia (UI-Press), Jakarta, h. 69 


\subsection{Hasil Analisa}

\subsubsection{Perlindungan Hukum Bagi Konsumen Terhadap Produk Kosmetik Impor Tanpa Izin Edar Yang Dijual Secara Online}

Izin edar merupakan bentuk persetujuan pendaftaran makanan ataupun kosmetik yang dikeluarkan oleh BPOM agar produk tersebut secara sah dapat diedarkan di wilayah Indonesia. Semua produk kosmetik yang akan dijual di wilayah Indonesia, baik yang berasal dari dalam negeri maupun yang diimpor dari luar negeri harus melalui pendaftaran untuk mendapatkan nomor izin edar yang dikeluarkan BPOM. Dimana bagi BPOM nomor pendaftaran tersebut berguna untuk mengawasi produk-produk yang beredar di pasaran, sehingga apabila terjadi suatu permasalahan akan mudah ditelusuri siapa pelakunya. ${ }^{10}$

Perlindungan hukum terhadap konsumen telah diatur di dalam Undang-Undang No. 8 Tahun 1999 tentang Perlindungan Konsumen. Hal-hal yang diatur antara lain hak dan kewajiban konsumen, hak dan kewajiban pelaku usaha, perbuatan-perbuatan yang dilarang pelaku usaha, tanggung jawab pelaku usaha, serta pembinaan dan pengawasan pemerintah. Perlindungan hukum yang diatur dalam Undang-Undang Perlindungan Konsumen bertujuan untuk memberikan perlindungan terhadap hak-hak konsumen termasuk

10 Edtriani Meliza, 2014. Pelaksanaan Pengawasan Balai Besar Pengawasan Obat Dan Makanan (BBPOM) Terhadap Peredaran Makanan Dan Minuman Tanpa Izin Edar (TIE) Di Kota Pekanbaru Tahun 2012, Jurnal Online Mahasiswa (JOM) Bidang Ilmu Sosial Dan Ilmu Politik, h. 10 
konsumen yang membeli produk konsmetik impor yang dijual secara online. ${ }^{11}$

Mengenai hak konsumen diatur dalam Pasal 4 UUPK,pada huruf adan huruf c yang menyatakan bahwa konsumen berhak atas kenyamanan, keamanan, dan keselamatan dalam mengonsumsi barang/jasa dan konsumen berhak atas informasi yang jelas, jujur dan benar mengenai kondisi jaminan barang/jasa. Konsumen berhak mendapatkan keamanan dari barang/jasa yang ditawarkan kepadanya, produk barang/jasa itu tidak boleh membahayakan jika dikonsumsi sehingga konsumen tidak dirugikan baik secara jasmani dan rohani, selain itu hak untuk keamanan ini penting untuk diutamakan. ${ }^{12}$

Disamping hak-hak dalam Pasal 4, terdapat juga hak-hak konsumen yang dirumuskan khususnya dalam Pasal 7 UUPK yang mengatur tentang kewajiban pelaku usaha. Dalam Pasal 8 UUPK mengatur mengenai perbuatan yang dilarang bagi pelaku usaha yang pada intinya pasal ini ditujukan pada dua hal yaitu: larangan memproduksi barang/jasa dan larangan memperdagangkan barang/jasa yang tidak sesuai dengan standar mutu. ${ }^{13}$ Apabila pelaku usaha memperdagangkan kosmetik impor yang termasuk perbuatan yang dilarang bagi pelaku usaha sebagaimana diatur dalam Pasal 8 ayat (4) UUPK, maka barang tersebut wajib ditarik dari peredarannya.

\footnotetext{
${ }^{11}$ Celina Tri Siwi Kristiyanti, op.cit, h. 30

${ }^{12}$ Ibid, h. 33

${ }^{13}$ Sutarman Yodo, 2011, Hukum Perlindungan Konsumen, PT Raja Grafindo Persada, Jakarta, h. 65-66
} 
Dalam hal perlindungan konsumen atas produk kosmetik impor yang telah dikonsumsi dan pada akhirnya menimbulkan kerugian kepada konsumen, maka telah diatur didalam ketentuan Pasal 19 ayat (1) dan (2) UUPK mengenai Tanggung Jawab Pelaku Usaha, yang pada intinya menyatakan bahwa pelaku usaha bertanggungjawab memberikan ganti rugi atas kerusakan, pencemaran, dan kerugian konsumen akibat mengkonsumsi barang/jasa yang dihasilkan atau diperdagangkan. Ganti rugi ini dapat berupa pengembalian uang, penggantian barang/jasa yang sejenis, perawatan kesehatan atau pemberian santunan yang sesuai dengan ketentuan Pasal 61 UUPK. Mengenai pemberian ganti rugi sebagaimana diatur dalam Pasal 19 ayat (1) dan ayat (2) tidak menghapuskan kemungkinan adanya tuntutan pidana berdasarkan pembuktian lebih lanjut mengenai adanya unsur kesalahan. Dan dapat digugat melalui badan penyelesaian sengketa konsumen atau mengajukannya ke badan peradilan di tempat kedudukan konsumen sesuai dengan Pasal 23 dan Pasal 62 UUPK.

\subsubsection{Bentuk Pengawasan Yang Dilakukan Oleh BBPOM Denpasar Atas Produk Kosmetik Impor Tanpa Izin Edar Yang Dijual Bebas Secara Online.}

Balai Besar Pengawas Obat dan Makanan (BBPOM) atau dikenal juga dengan istilah Organisasi Unit Pelaksana Teknis BPOM yang merupakan unit organisasi yang melaksanakan tugas dan fungsi pengawasan obat dan makanan di wilayah kerjanya. Dalam ketentuan Pasal 4 huruf a Peraturan Presiden No. 80 Tahun 2017 tentang BPOM, menyatakan bahwa "Dalam melaksanakan tugas pengawasan, BPOM mempunyai kewenangan untuk menerbitkan izin 
edar produk dan sertifikat sesuai dengan standard an persyaratan keamanan, khasiat/manfaat dan mutu, sesuai dengan peraturan perundang-undangan". Kosmetik impor yang dijual secara online haruslah memiliki izin edar, namun hasil penertiban yang dilakukan oleh Balai Besar Pengawasan Obat dan Makanan (BBPOM) Denpasar, berhasil menemukan 247 jenis kosmetik impor setara dengan 10.751 kemasan kosmetik, yang tidak memiliki izin edar. ${ }^{14}$

Adapun beberapa faktor yang menyebabkan pelaku usaha tidak mendaftarkan produknya untuk mendapatkan izin edar dari BBPOM, menurut pendapat Bapak I Putu Mahentoro selaku staf Penyidikan pada BBPOM Denpasar,anatar lain :

1. Kurangnya pemahaman mengenai prosedur-prosedur sebelum produk dipasarkan harus didaftarakan terlebih dahulu pada instansi terkait seperti BPOM dan Kemendag RI dan tata cara proses mengenai pendaftaran barang impor.

2. Takut dikenanakan bea masuk dan pajak sehingga menambah biaya produksi mengakibatkan harga produknya menjadi tinggi.

3. Ingin serba instan tanpa melalui proses yang panjang karena untuk mendapatkan barang yang murah dan cepat mendapat keuntungan yang diinginkan.

Dalam pengawasan penjualan kosmetik melalui media elektronik (online), dewasa ini masih sulit untuk diawasi secara keseluruhannya, namun tindakan pengawasan yang dilakukan oleh BBPOM Denpasar, dalam pelaksanaan pemeriksaan terhadap

\footnotetext{
${ }^{14}$ Nandhang Astika, Loc.cit
} 
kegiatan produksi, impor, peredaran, penggunaan dan promosi kosmetik meliputi kewenangan untuk :

a. Memasuki setiap tempat yang diduga digunakan dalam kegiatan produksi, impor distribusi, penyimpanan, pengangkutan, dan penyerahan kosmetik untuk memeriksa, meneliti, dan mengambil contoh segala sesuatu yang digunakan dalam kegiatan produksi, impor, distribusi, penyimpanan, pengangkutan dan penyerahan kosmetik.

b. Melakukan pemeriksaan dokumen atau catatan lain yang memuat atau diduga memuat keterangan mengenai kegiatan produksi, impor, distribusi, penyimpanan, pengangkutan, dan penyerahan kosmetik.

c. Memerintahkan untuk memperlihatkan izin usaha dan dokumen lainnya. ${ }^{15}$

Karena pengawasan tehadap kosmetik yang dijual melalui media elektronik (online) dewasa ini masih sulit untuk diawasi secara keseluruhan, maka menurut Bapak I Putu Mahentoro selaku staf penyidikan pada BBPOM Denpasar menyatakan bahwa BBPOM menghimbau kepada masyarakat apabila menemukan kosmetik dan dianggap mengandung bahan berbahaya didalamnya maka diharapkan untuk melapor kepada BBPOM Denpasar, agar dapat dilakukan tindak lanjut.

Pelanggaran terhadap peredaran kosmetik yang tidak memenuhi standar mutu dan tidak memiliki izin edar sebagaimana

15 Sri Arlina, 2018, "Perlindungan Konsumen Dalam Transaksi Jual Beli Online Produk Kosmetik (Pemutih Wajah) yang Mengandung Zat Berbahaya Berdasarkan Undang-Undang Nomor 8 Tahun 1999", Jurnal Fakultas Hukum Universitas Islam Riau 
diatur dalam Pasal 13 Peraturan Kepala Badan Pengawasan Obat dan Makanan Republik Indonesia Nomor HK.03.1.23.12.11.10052 Tahun 2011 tentang Pengawasan Produksi dan Peredaran Kosmetika, dapat dikenakan sanksi administratif maupun sanksi pidana, diantaranya peringatan tertulis, larangan mengedarkan kosmetik untuk sementara, penerikan kosmetik dari peredaran, pemusnahan kosmetik, pemberhentian sementara kegiatan produksi dan importasi, pembatalan notofikasi atau penutupan sementara akses online pengajuan permohonan notifikasi.

\section{Penutup}

\subsection{Kesimpulan}

1. Perlindungan hukum bagi konsumen terhadap peredaran kosmetik impor tanpa izin edar di Indonesia diatur dalam Undang-Undang No 8 Tahun 1999 tentang Perlindungan Konsumen, yaitu pada Pasal 4 tentang hak-hak konsumen dan Pasal 7 tentang kewajiban pelaku usaha. Dan apabila suatu produk kosmetik tersebut tidak sesuai dengan standar dan persyaratan yang telah ditentuka, maka sesuai ketentuan Pasal 8 ayat (4) UUPK, produk kosmetik tersebut wajib ditarik dari peredaran. Dan dalam hal perlindungan konsumen atas produk kosmetik impor yang telah dikonsumsinya dan pada akhirnya menimbulkan kerugian maka hal tersebut merupakan tanggung jawab dari pelaku usaha yang harus bertanggungjawab memberikan ganti rugi terhadap konsumen sesuai dengan ketentuan Pasal 19 UUPK.

2. Dalam pengawasan penjualan kosmetik melalui media elektronik (online) yang dilakukan oleh BBPOM Denpasar, 
dewasa ini masih sulit untuk diawasi secara keseluruhannya, hal ini terlihat masih banyaknya beredar produk kosmetik impor yang belum terdaftar yang dijual secara online. Faktorfaktor yang mempengaruhi beredarnya kosmetik impor yang tidak terdaftar di BBPOM Denpasar dikarenakan pelaku usaha yang kurang paham mengenai ketentuan dan proses proses pendaftaran barang impor khususnya kosmetik impor, selain itu pelaku usaha yang ingin serba instan tanpa melalui proses yang panjang karena untuk mendapatkan barang yang murah dan cerpat untuk mendapatkan keuntungan yang diinginkan.

\subsection{Saran}

Harus ada kerjasama yang baik antara Pemerintah, BPOM, dan aparat penegak hukum lainnya dalam upaya perlindungan konsumen atas peredaran kosmetik imporyang dijual bebas secara online.Selain itu perlu diadakannya sosialisasi kepada masyarakat selaku konsumen agar lebih teliti dan berhati-hati sebelum memesan produk kosmetik, memeriksa komposisi bahan aman atau tidak digunakan pada kulit, dan yang terpenting telah lulus uji dan memiliki izin edar oleh BPOM.

\section{Daftar Pustaka}

\section{Buku}

Ali, H. Zainuddin, 2016, Metode Penelitian Hukum, Sinar Grafika, Jakarta

Kristiyanti ,Celina Tri Siwi, 2011, Hukum Perlindungan Konsumen, Sinar Grafika, Jakarta.

Marzuki, Peter Mahmud, 2011, Penelitian Hukum, Kencana, Jakarta. 
Miru, Ahmad, 2011, Prinsip-Prinsip Perlindungan Hukum Bagi Konsumen di Indonesia, Rajawali Pers, Jakarta.

Soekanto, Soerjono, 2015, Pengantar Penelitian Hukum, Cet. 3, Penerbit Universitas Indonesia (UI-Press), Jakarta.

Suratman, 2015, Metode Penelitian Hukum, ALFABETA, Bandung.

Universitas Udayana, Fakultas Hukum, 2013, Pedoman Pendidikan Fakultas Hukum Universitas Udayana, Denpasar.

Yodo, Sutarman, 2011, Hukum Perlindungan Konsumen, PT Raja Grafindo Persada, Jakarta.

\section{Jurnal}

Sri Arlina, 2018, "Perlindungan Konsumen Dalam Transaksi Jual Beli Online Produk Kosmetik (Pemutih Wajah) yang Mengandung Zat Berbahaya Berdasarkan Undang-Undang Nomor 8 Tahun 1999", Jurnal Fakultas Hukum Universitas Islam Riau.

M, Salsabilla, 2015. Perlindungan Konsumen Terhadap Produk Kosmetik Yang Dijual Secara Online Di Kota Banda Aceh, Jurnal Fakultas Hukum Universitas Syiah Kuala.

Meliza, Edtriani, 2014. Pelaksanaan Pengawasan Balai Besar Pengawasan Obat Dan Makanan (BBPOM) Terhadap Peredaran Makanan Dan Minuman Tanpa Izin Edar (TIE) Di Kota Pekanbaru Tahun 2012, Jurnal Online Mahasiswa (JOM) Bidang Ilmu Sosial Dan Ilmu Politik.

\section{Internet}

Nandhang Astika, 2018, "BPOM Sita Ribuan Kosmetik Berbahaya yang Beredar di Bali”, URL :https://news.detik.com/berita/4122471/bpom-sita-ribuankosmetik-berbahaya-yang-beredar-di-bali

\section{Peraturan Perundang-Undangan}

Undang-Undang Dasar Negara Republik Indonesia 
Undang-Undang Republik Indonesia Nomor 8 Tahun 1999 tentang Perlindungan Konsumen

Peraturan Presiden Republik Indonesia Nomor 80 Tahun 2017 tentang Badan Pengawasan Obat dan Makanan

Keputusan Kepala Badan Pengawasan Obat dan Makanan Republik Indonesia Nomor HK.00.05.4.1745 tentang Kosmetik

Keputusan Kepala Badan Pengawasan Obat dan Makanan Republik Indonesia Nomor 03.1.23.12.11.10052 Tahun 2011 tentang Pengawasan Produksi dan Peredaran Kosmetik 